\section{Magnetic Targeting of Magneto- Plasmonic Nanoparticles and Their Effects on Temperature Profile of NIR Laser Irradiated to CT26 Tumor in BALB/C Mice}

\author{
Ziaeddin Abed ${ }^{1 \oplus}$, Ali Shakeri-Zadeh², Nazila Eyvazzadeh*๑
}

\begin{abstract}
Background: Photothermal therapy (PTT) is a promising method in the field of cancer hyperthermia. In this method, interaction between laser light and photosensitizer material, such as plasmonic nanoparticles, leads into a localized heating. Recent efforts in the area of PTT aim to exploit targeting strategies for preferential accumulation of plasmonic nanoparticles within the tumor.

Objective: To investigate the impact of magneto-plasmonic $\left(\mathrm{Au} @ \mathrm{Fe}_{2} \mathrm{O}_{3}\right)$

nanoparticles on temperature profile of CT26 tumor, bearing mice were irradiated by NIR laser.
\end{abstract}

Material and Methods: In this in vivo study, $\mathrm{Au} @ \mathrm{Fe}_{2} \mathrm{O}_{3} \mathrm{NPs}$ were injected intraperitoneally to Balb/c mice bearing CT26 colorectal tumor. Immediately after injection, a magnet (magnetic field strength of 0.4 Tesla) was placed on the tumor site for 6 hours in order to concentrate nanoparticles inside the tumor. In the next step, the tumors were exposed with NIR laser source $\left(808 \mathrm{~nm} ; 2 \mathrm{~W} / \mathrm{cm}^{2} ; 5 \mathrm{~min}\right)$.

Results: Tumor temperature without magnetic targeting increased $\sim 7 \pm 0.9^{\circ} \mathrm{C}$ after NIR irradiation, whereas the tumors in magnetic targeted group experienced a temperature rise of $\sim 12 \pm 1.4^{\circ} \mathrm{C}$.

Conclusion: It is concluded that $\mathrm{Au} @ \mathrm{Fe}_{2} \mathrm{O}_{3}$ nanoparticle is a good candidate for therapeutic nanostructure in cancer photothermal therapy.

Citation: Abed Z, Shakeri-Zadeh A, Eyvazzadeh N. Magnetic Targeting of Magneto-Plasmonic Nanoparticles and Their Effects on Temperature Profile of NIR Laser Irradiated to CT26 Tumor in BALB/C Mice. J Biomed Phys Eng. 2021;11(3):281-288. doi: 10.31661/jbpe.v0i0.1032.

\section{Keywords}

Cancer; Nanomedicine; Nanoparticles; Laser Therapy; Hyperthermia

\section{Introduction}

olon cancer is known as the third most prevalent cancer and the
third cause of death from cancer in the United States. According
to global statistics, 9 percent of men and 7 percent of women are
involved with colon cancer in the world [1]. Since conventional cancer
therapies, including surgery, chemotherapy and radiotherapy have not
been efficient enough due to major constraints, new treatments such as
hyperthermia have emerged to provide definitive or adjuvant therapy
$[2,3]$. Hyperthermia is referred to a method in which the desired tissue
is exposed to high temperature. If the target temperature reaches 41 -

${ }^{1} \mathrm{MSc}$, Radiation Research Center, Allied Medical Sciences

School, AJA University of Medical Sciences,

Tehran, Iran

${ }^{2} \mathrm{PhD}$, Department of Medical Physics, School of Medicine, Iran University of Medical Sciences (IUMS), Tehran, Iran

${ }^{3} \mathrm{PhD}$, Radiation Research Center, Allied Medical Sciences

School, AJA University of Medical Sciences, Tehran, Iran

*Corresponding author: Nazila Eyvazzadeh Radiation Research Center, Allied Medical Sciences School, AJA University of Medical Sciences, Tehran, Iran E-mail: nazila9263@ yahoo.com

Received: 30 September 2018 Accepted: 27 October 2018 
$48^{\circ} \mathrm{C}$, hyperthermia can be used as auxiliary treatment for chemotherapy and radiotherapy. Beyond the temperature of $48^{\circ} \mathrm{C}$, hyperthermia alone causes necrosis and cell death [4-6]. On the other hand, conventional hyperthermia due to temperature gradients (temperature drop from skin surface to depth) is not suitable method for in-depth lesions, because healthy tissues located between the external heat source and the lesion receive more temperature than the target tissue, resulting in serious side effects $[3,7]$. Many efforts were made to resolve this problem. The use of nanoparticle as hyperthermia agents is a smart idea that can address this drawback. In this modern hyperthermia method, nanoparticles absorb energy from external source and convert it to excessive heat $[8,9]$.

Laser is one of the most used sources of hyperthermia for superficial treatments. Photothermal therapy (PTT) is one of the important branches of hyperthermia arising from interaction between laser and nanoparticle such as gold. In this method, gold nanoparticle receive incident light and convert it to heat based on Surface Plasmon resonance (SPR) phenomena [10]. As a result, with turning laser irradiation off, gold nanoparticles play the role of internal source making inverted temperature gradient (temperature drop from inside to the skin surface) [3]. The targeting subject of nanoparticles and their maximum accumulation within the tumor is another issue that is important in modern hyperthermia method. Todays, iron oxide nanoparticles with the capability of external targeting have attracted a lot of attention. These nanoparticles can be directed by the external magnetic field towards the desired target $[3,11,12]$.

In the photothermal therapies, nano particles that are sensitive to light, are located in cancerous cells and exposed to laser light [13]. At the time of laser irradiation to the atom of nanoparticles, the atomic electrons absorb laser photons and are excited toward higher energy levels. Since electrons are unstable in this case, they tend to return to the base state (lower energy level). By turning these electrons back to base, that extra energy will turn into heat. The most important advantage of photothermal therapy in the presence of a nanoparticle is the dramatic reduction in laser power density required for cancer treatment [3]. Studies show that only 3 minutes of continuous infrared laser irradiation with a power of $3.5 \mathrm{~W}$ is enough to kill the tumor cells by heat after the intravenous injection of a gold nanoparticle [14]. While in order to produce the same result, in the absence of gold nanoparticles, 10-minute irradiation of a high-power $10 \mathrm{~W}$ laser is required [15].

According to the literatures, it may be stated that the recent efforts in the area of PTT aims to exploit targeting strategies for preferential accumulation of plasmonic nanoparticles within the tumor. Here, we report the effect of magneto-plasmonic $\left(\mathrm{Au} @ \mathrm{Fe}_{2} \mathrm{O}_{3}\right)$ nanoparticles on temperature profile of CT26 tumor bearing mice irradiated by NIR laser.

\section{Material and Methods}

\section{Material}

In this in vivo study, iron (II) chloride tetrahydrate $(>99 \%)$, iron (III) chloride hexahydrate $(>99 \%)$, ammonia $(32 \%), \mathrm{HCl}$, and HNO3 were purchased from Merck (Darmstadt, Germany). Fetal bovine serum (FBS) and Roswell Park Memorial Institute (RPMI) 1640 were purchased from GIBCO (Invitrogen, Germany). Trypsin ethylenediaminetetraacetic acid (EDTA), Dimethyl sulfoxide (DMSO), penicillin-streptomycin solution, gold (III) chloride solution, all were prepared from Sigma-Aldrich (St Louis, MO).

Synthesis and characterization of $\mathrm{Au} @ \mathrm{Fe}_{2} \mathrm{O}_{3}$ core-shell NPs

The method of $\mathrm{Au} @ \mathrm{Fe}_{2} \mathrm{O}_{3}$ core-shell NPs preparation was reported, previously $[16,17]$. Briefly, the mentioned NP was synthesized according to the modified Lyon's iterative 
hydroxylamine-seeding procedure through the deposition of AuNPs on $\mathrm{Fe}_{2} \mathrm{O}_{3}$ NPs [18]. Characteristics of nanoparticles were also reported completely in our previous publications [17]. The nanoparticles were spherical and the hydrodynamic size distribution of nanoparticles was ranged from $20-50 \mathrm{~nm}$ with the highest frequency around $33 \mathrm{~nm}$. In addition, Zeta potential was reported $-17.9 \mathrm{mV}$. Finally, we demonstrated that the $\mathrm{Au} @ \mathrm{Fe}_{2} \mathrm{O}_{3}$ core-shell NPs highly absorbed the NIR wavelengths [17].

\section{In vivo experimental procedure}

BALB/c mice (male; 5-8 weeks; 18-25 g) were purchased from the Pasteur Institute of Iran. Animals were firstly kept under controlled light, temperature, and humidity conditions for one week. $2 \times 10^{6}$ CT26 cells suspended in $200 \mu \mathrm{l}$ RPMI 1640 solution were injected subcutaneously on the right flank of the mice. When the tumor volume approximately reached $150 \mathrm{~mm}^{3}$, the experiment was started. We randomly divided the mice into three groups (n per group=3). The treatments included: Laser,Au@ $\mathrm{Fe}_{2} \mathrm{O}_{3}+$ Laser, and Au@ $\mathrm{Fe}_{2} \mathrm{O}_{3}+$ Magnet + Laser. Nanoparticles suspension (volume $=200 \mu \mathrm{l}$; concentration $=50$ $\mu \mathrm{g} / \mathrm{ml}$ ) was intraperitoneally injected. The surface of the tumors was shaved before laser irradiation and then exposed to the laser beam $\left(2 \mathrm{~W} / \mathrm{cm}^{2} ; 5 \mathrm{~min}\right)$. In the combined treatment group, a time interval of $6 \mathrm{~h}$ was considered between NPs injection and laser exposure. Additionally, in the group, which the magnet was used, after nanoparticle injection, the magnet was placed on the tumor site for 6 hours immediately. During the laser irradiation, the temperature was monitored and recorded every minute by the Testo $875-1 \mathrm{i}$ infrared camera. Figure 1 shows the examples of mice received intraperitoneal injection (a), intraperitoneal in-
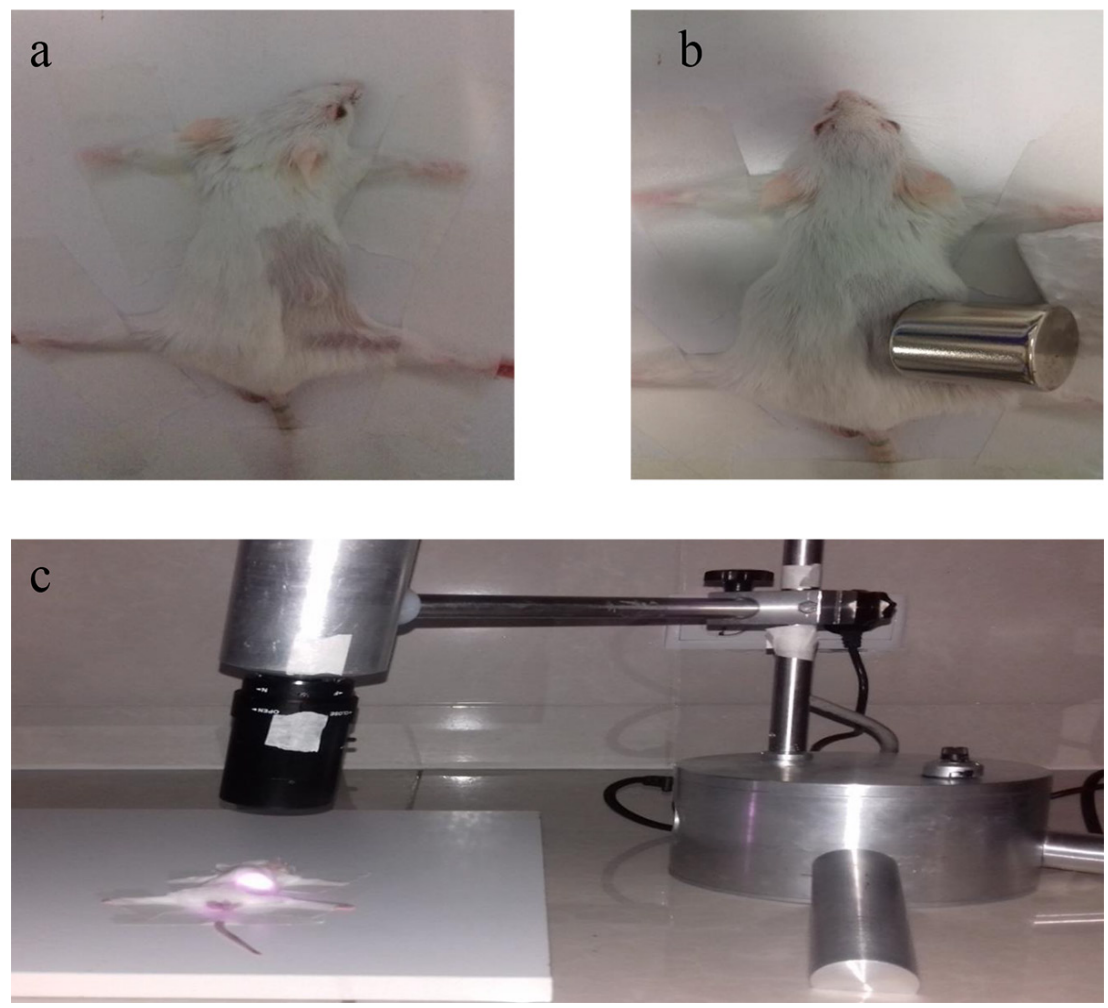

Figure 1: The examples of mice received intraperitoneal injection (a), intraperitoneal injection + Magnet (b), and laser irradiation (c). 
jection + Magnet (b), and laser irradiation (c).

\section{Statistical analysis}

We presented data as the mean values \pm standard deviations. The SPSS software was utilized for data analysis (version 11). The one-way analysis of variance (ANOVA) followed by Tukey's test as the post-hoc analysis were used to assess the differences between the treated and control groups. The value of $\mathrm{P}$ $<0.05$ was considered statistically significant.

\section{Results}

In order to evaluate the in vivo photothermal capability of nanoparticles, the temperature profile of the tumor with and without inclusion of the $\mathrm{Au} @ \mathrm{Fe}_{2} \mathrm{O}_{3}$ nanoparticles was recorded using infrared thermal imaging. Figure 2 shows the example of thermal maps of the mice in various groups. In Figure 2a, thermal distribution due to NIR laser irradiation is observable where the $\mathrm{T}_{\text {max }}$ changed from $35.5^{\circ} \mathrm{C}$ (before irradiation) to $41.5^{\circ} \mathrm{C}$ (after irradiation). Figure $2 \mathrm{~b}$ shows that $\mathrm{T}_{\max }$ was $36.5^{\circ} \mathrm{C}$ in tumor of the mouse injected by nanoparticles intraperitoneally. For this mouse, $\mathrm{T}_{\text {max }}$ increased to $44.1^{\circ} \mathrm{C}$ when irradiating with NIR laser. Then, the impact of magnetic targeting

\section{$\mathbf{a}$}
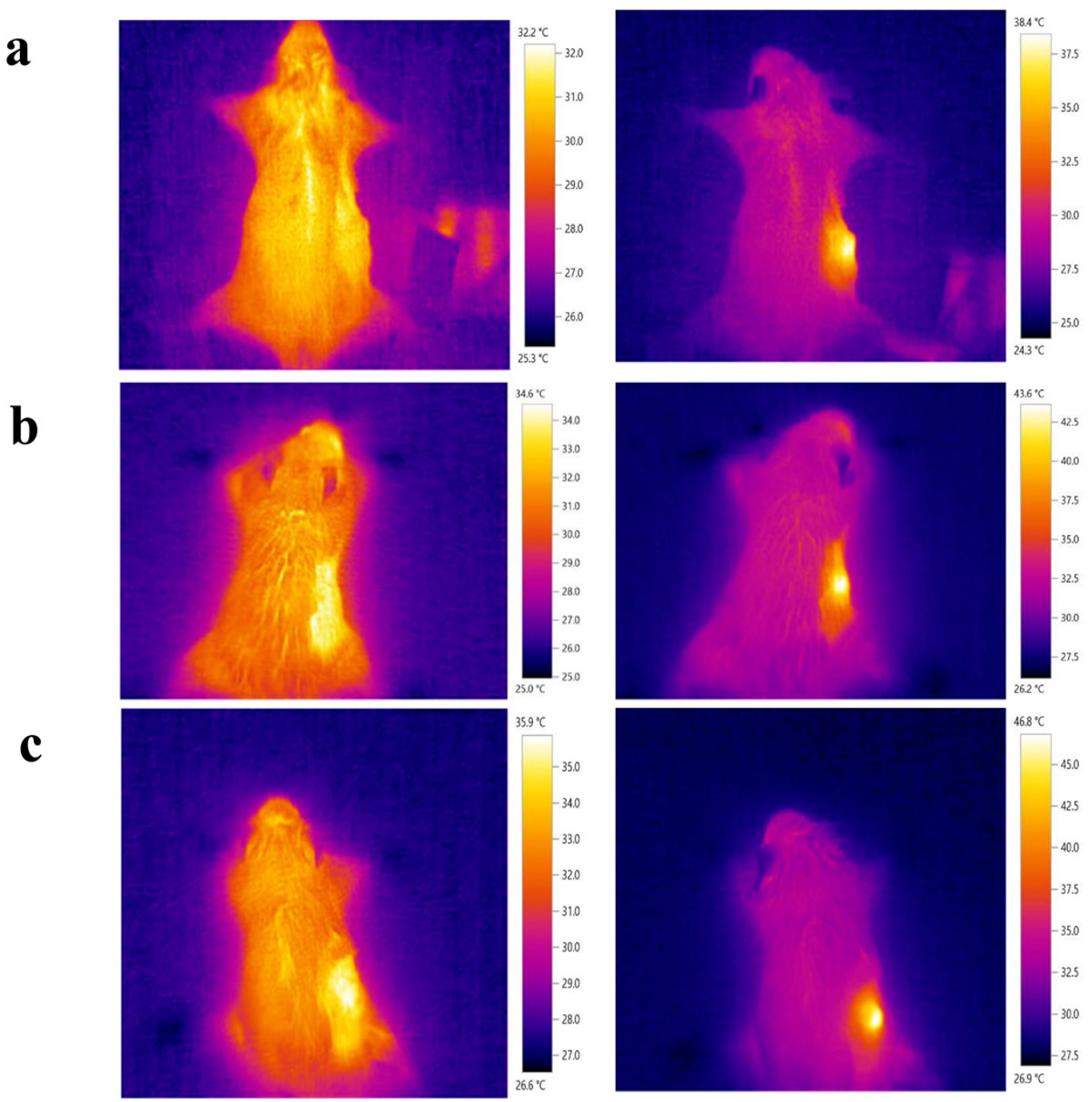

Figure 2: The example of infrared camera images of various groups; laser (a), laser + intraperitoneal injection $(b)$, laser + intraperitoneal injection + magnet $(c)$. 
Magneto-Plasmonic Nanoparticles for Photothermal Therapy

was investigated. Figure $2 \mathrm{c}$ shows the obtained results for the mouse received nanoparticles plus magnetic targeting and then irradiated by laser. According to this part of Figure 2, it is seen that the tumor experienced $12^{\circ} \mathrm{C}$ increase in temperature.

According to the example images shown in Figure 2, we made the Figure 3 to show the incremental temperature profile of the tumor during laser irradiation $\left(2 \mathrm{~W} / \mathrm{cm}^{2}, 5 \mathrm{~min}\right)$. Compared to the tumor without $\mathrm{Au} @ \mathrm{Fe}_{2} \mathrm{O}_{3}$ nanoparticles that showed a mild temperature rise under laser irradiation $\left(\Delta \mathrm{T}=6^{\circ} \mathrm{C}\right)$, the tumors treated with the $\mathrm{Au} @ \mathrm{Fe}_{2} \mathrm{O}_{3}$ nanoparticles prior to laser irradiation reached $\Delta \mathrm{T} \sim 7.2^{\circ} \mathrm{C}$ for non-targeted group and $\Delta \mathrm{T} \sim 12.3^{\circ} \mathrm{C}$ for magnetic targeted group.

\section{Discussion}

The cell uptake depends on various factors such as the size, shape, and surface charge of the nanoparticle. Some studies showed that the absorption of nanorods by the cells is greater than other forms of nanoparticles, but in sizes less than $100 \mathrm{~nm}$, spherical nanoparticles are better absorbed. From point view of cell uptake, the best size of the nanoparticle is estimated to be $20-60 \mathrm{~nm}$. The charge of nanoparticles also affects the cell uptake process. Due to negative charge of the cell membrane, the absorption of cationic particles will be higher than other particles $[19,20]$. The nanoparticles used in this study were spherical and had a size range of 20-50 $\mathrm{nm}$. Thus, the nanoparticles used in this study may have high level of cell uptake. Their zeta potential was measured $-17.9 \mathrm{Mv}$, indicating the agglomeration of these nanoparticles were not at high level and had a good stability. Therefore, the synthesized nanoparticles had acceptable characteristics to be used in vivo study.

Many studies confirm the photothermal properties of gold nanoparticles. When a metal particle is exposed by light, the conduction layer electrons oscillate. This process, known as SPR, is very strong in metal based nanoparticles like gold. The SPR peak of AuNPs is occurred at $520 \mathrm{~nm}$ (visible range). Such a wavelength range for lasers is appropriate to treat the superficial tumors. To

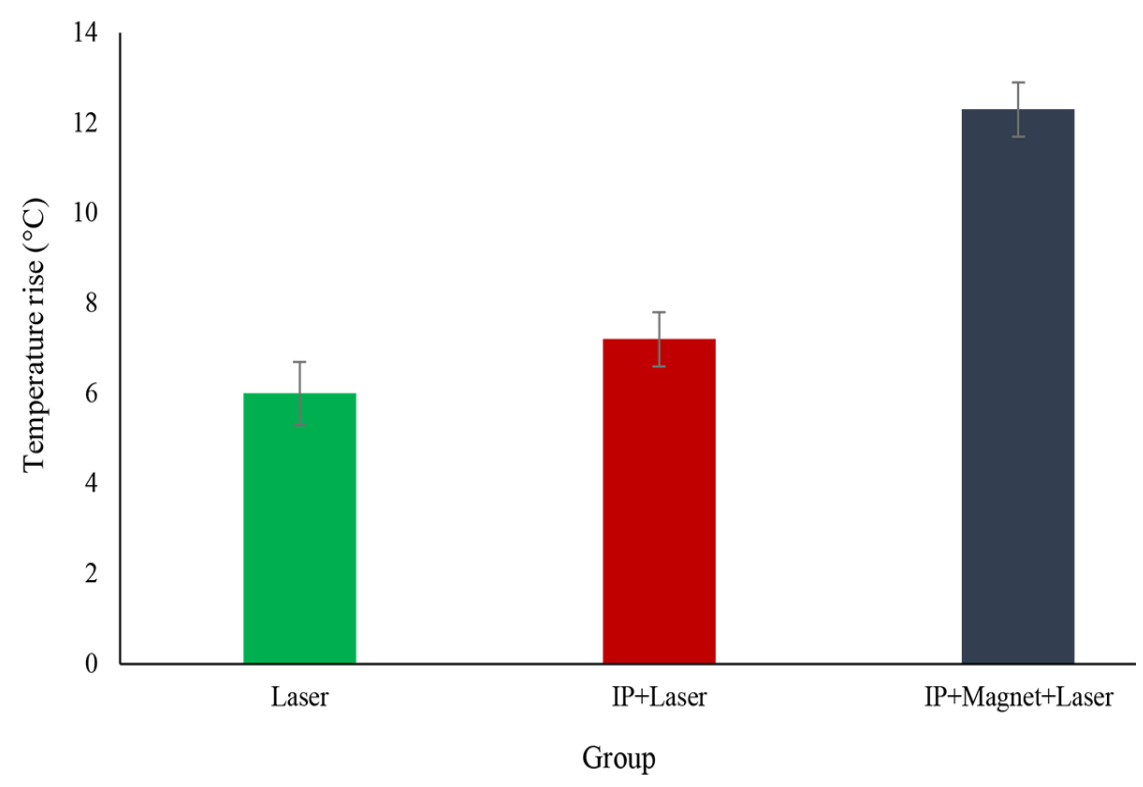

Figure 3: The variations in temperature caused by laser irradiation $808 \mathrm{~nm}$ for 5 minutes in three groups of mice; (i) laser, (ii) intraperitoneal injection + laser, and (iii) intraperitoneal injection + laser + magnet. 
treat the tumors located in deeper sites, the NIR lasers are usually utilized. Therefore, the nanoparticles activated in the NIR region are better choices in PTT. Changing the particle size, shape, structure and composition can change the SPR absorption wavelength of the nanoparticles. The use of a gold nanoshell displaces SPR wavelength into the NIR region. In this study, we have used $\mathrm{Au} @ \mathrm{Fe}_{2} \mathrm{O}_{3}$ coreshell NP as a photosensitizer of NIR laser. In fact, the wavelength peak of the $\mathrm{Au} @ \mathrm{Fe}_{2} \mathrm{O}_{3}$ was measured at $\sim 580 \mathrm{~nm}$, but its absorbance value is not dropped significantly after $580 \mathrm{~nm}$ and continued to $810 \mathrm{~nm}$ [21].

In the present study, three various groups of mice were exposed to laser as mentioned in previous section. In our studies, temperature of tumor surface in mice treated with laser alone increased from $35.5 \pm 1.6$ to $41.5 \pm 0.9{ }^{\circ} \mathrm{C}$ in 5 minutes. For the group in which the mice treated with nanoparticles injected intraperitoneally and laser, the temperature changes were from $36.9 \pm 1.9$ to $44.1 \pm 1.4{ }^{\circ} \mathrm{C}$. For the group in which we put magnet on tumor site after intraperitoneally injection and then irradiated by laser, the temperature was enhanced from 34.5 \pm 1.3 to $46.8 \pm 0.5{ }^{\circ} \mathrm{C}$.

The temperature rise did not change significantly when the tumor was only exposed to laser. The presence of gold-coated iron oxide nanoparticles played an important role in increasing the temperature. In other words, the overlapping of the nanoparticles SPR with laser wavelength caused the oscillation of nanoparticle electrons and increased tumor temperature locally [22]. These results are comparable with the studies reported by Chen and Liu [23, 24]. After injection of polypyrrole nanoparticles into Balb/c mice, Chen et al. exposed $808 \mathrm{~nm}$ laser to the tumor. Their results showed that the tumor temperature reached $60{ }^{\circ} \mathrm{C}$ after 5 minutes irradiation, while in the laser group temperature rise of tumor surface was shown only $3{ }^{\circ} \mathrm{C}$. The reason for this temperature rise was the absorption of NIR light by the nanoparticles [23]. Liu et al. observed temperature changes of $21^{\circ} \mathrm{C}$ in the presence of manganese oxide nanoparticles and 808 $\mathrm{nm}$ laser irradiation for 4 minutes in mice, whereas there was no significant temperature increase in the mice received laser alone. They also observed that the temperature only increased in a small area around the tumor and other organs would not be affected due to the NIR laser spatial control [24]. There is a consistency between the results observed in this study and the data published by Liu et al. This is because the images recorded by the infrared camera (Figure 2) showed that the temperature enhancement was limited to the tumor area and did not occur in the surrounding organs.

\section{Conclusion}

The goal of current study was to determine the in vivo photosensitizing effects of $\mathrm{Au} @$ $\mathrm{Fe}_{2} \mathrm{O}_{3}$ core-shell NPs. Also, it was found that NPs can be highly accumulated in the tumor site using magnetic targeting method. Our findings demonstrated that the interaction of NIR laser and the accumulated nanoparticles caused remarkable temperature rise in the tumor. Consequently, it may be stated that Au@ $\mathrm{Fe}_{2} \mathrm{O}_{3}$ core-shell NP is an appropriate and targetable photosensitizer agent useable in the process of cancer photothermal therapy.

\section{Conflict of Interest}

None

\section{References}

1. Siegel RL, Miller KD, Jemal A. Cancer Statistics, 2017. CA Cancer J Clin. 2017;67:7-30. doi: 10.3322/caac.21387. PubMed PMID: 28055103.

2. Hehr T, Wust P, Bamberg M, Budach W. Current and potential role of thermoradiotherapy for solid tumours. Onkologie. 2003;26:295302. doi: 10.1159/000071628. PubMed PMID: 12845217.

3. Beik J, Abed Z, Ghoreishi FS, Hosseini-Nami S, Mehrzadi S, Shakeri-Zadeh A, et al. Nanotechnology in hyperthermia cancer therapy: From fundamental principles to advanced applica- 
Magneto-Plasmonic Nanoparticles for Photothermal Therapy

tions. J Control Release. 2016;235:205-21. doi: 10.1016/j.jconrel.2016.05.062. PubMed PMID: 27264551.

4. Banobre-Lopez M, Teijeiro A, Rivas J. Magnetic nanoparticle-based hyperthermia for cancer treatment. Rep Pract Oncol Radiother. 2013;18:397-400. doi: 10.1016/j. rpor.2013.09.011. PubMed PMID: 24416585. PubMed PMCID: PMC3863197.

5. Abadeer NS, Murphy CJ. Recent progress in cancer thermal therapy using gold nanoparticles. J Phys Chem C. 2016;120:4691716. doi: 10.1021/acs.jpcc.5b11232.

6. Jaque D, Martinez Maestro L, Del Rosal B, Haro-Gonzalez P, Benayas A, Plaza JL, et al. Nanoparticles for photothermal therapies. Nanoscale. 2014;6:9494-530. doi: 10.1039/ c4nr00708e. PubMed PMID: 25030381.

7. Chatterjee DK, Diagaradjane P, Krishnan S. Nanoparticle-mediated hyperthermia in cancer therapy. Ther Deliv. 2011;2:1001-14. PubMed PMID: 22506095. PubMed PMCID: PMC3323111.

8. Raoof M, Cisneros BT, Corr SJ, Palalon F, Curley SA, Koshkina NV. Tumor selective hyperthermia induced by short-wave capacitively-coupled RF electric-fields. PLoS One. 2013;8:e68506. doi: 10.1371/journal.pone.0068506. PubMed PMID: 23861912. PubMed PMCID: PMC3701653.

9. Glazer ES, Massey KL, Zhu C, Curley SA. Pancreatic carcinoma cells are susceptible to noninvasive radio frequency fields after treatment with targeted gold nanoparticles. Surgery. 2010;148:319-24. doi: 10.1016/j. surg.2010.04.025. PubMed PMID: 20541785. PubMed PMCID: PMC2904623.

10. Hosseini V, Mirrahimi M, Shakeri-Zadeh A, Koosha F, Ghalandari B, Maleki S, et al. Multimodal cancer cell therapy using Au@ Fe203 core-shell nanoparticles in combination with photo-thermo-radiotherapy. Photodiagnosis Photodyn Ther. 2018;24:129-35. doi: 10.1016/j. pdpdt.2018.08.003.

11. Li X, Wei J, Aifantis KE, Fan Y, Feng Q, Cui $F Z$, et al. Current investigations into magnetic nanoparticles for biomedical applications. J Biomed Mater Res A. 2016;104:1285-96. doi: 10.1002/jbm.a.35654. PubMed PMID: 26779606.

12. Elsherbini AA, Saber M, Aggag M, El-Shahawy A,
Shokier HA. Magnetic nanoparticle-induced hyperthermia treatment under magnetic resonance imaging. Magn Reson Imaging. 2011;29:27280. doi: $10.1016 /$ j.mri.2010.08.010. PubMed PMID: 21145190.

13.Schwartz JA, Price RE, Gill-Sharp KL, Sang $\mathrm{KL}$, Khorchani J, Goodwin BS, et al. Selective nanoparticle-directed ablation of the canine prostate. Lasers Surg Med. 2011;43:21320. doi: 10.1002/lsm.21039. PubMed PMID: 21412805.

14. Kwatra D, Venugopal A, Anant S. Nanoparticles in radiation therapy: a summary of various approaches to enhance radiosensitization in cancer. Trans/ Cancer Res. 2013;2:330-42.

15. Müller GJ, Roggan A. Laser-induced interstitial thermotherapy. Bellingham, Wash: SPIE Optical Engineering Press; 1995.

16. Kang YS, Risbud S, Rabolt JF, Stroeve P. Synthesis and characterization of nanometer-size Fe304 and $\gamma$-Fe203 particles. Chem Mater. 1996;8:2209-11.

17. Mirrahimi M, Hosseini V, Kamrava SK, Attaran $\mathrm{N}$, Beik J, Kooranifar S, et al. Selective heat generation in cancer cells using a combination of $808 \mathrm{~nm}$ laser irradiation and the folate-conjugated Fe203@ Au nanocomplex. Artif Cells Nanomed Biotechnol. 2018;46:241-53.

18. Lyon JL, Fleming DA, Stone MB, Schiffer P, Williams ME. Synthesis of Fe oxide core/Au shell nanoparticles by iterative hydroxylamine seeding. Nano Letters. 2004;4:719-23. doi: 10.1021/nl035253f.

19. Albanese A, Tang PS, Chan WC. The effect of nanoparticle size, shape, and surface chemistry on biological systems. Annu Rev Biomed Eng. 2012;14:1-16. doi: 10.1146/annurevbioeng-071811-150124. PubMed PMID: 22524388.

20.Zhang S, Li J, Lykotrafitis G, Bao G, Suresh S. Size-Dependent Endocytosis of Nanoparticles. Adv Mater. 2009;21:419-24. doi: 10.1002/ adma.200801393. PubMed PMID: 19606281. PubMed PMCID: PMC2709876.

21. Huang X, El-Sayed MA. Gold nanoparticles: optical properties and implementations in cancer diagnosis and photothermal therapy. $J$ Adv Res. 2010;1:13-28.

22. Green HN, Crockett SD, Martyshkin DV, Singh KP, Grizzle WE, Rosenthal EL, et al. A histo- 
logical evaluation and in vivo assessment of intratumoral near infrared photothermal nanotherapy-induced tumor regression. Int J Nanomedicine. 2014;9:5093-102. doi: 10.2147/IJN. S60648. PubMed PMID: 25395847. PubMed PMCID: PMC4227627.

23. Chen M, Fang X, Tang S, Zheng N. Polypyrrole nanoparticles for high-performance in vivo near-infrared photothermal cancer ther- apy. Chem Commun (Camb). 2012;48:89346. doi: 10.1039/c2cc34463g. PubMed PMID: 22847451.

24.Liu Q, Sun C, He Q, Liu D, Khalil A, Xiang T, et al. Ultrathin carbon layer coated $\mathrm{MoO}_{2}$ nanoparticles for high-performance near-infrared photothermal cancer therapy. Chemical Communications. 2015;51:10054-7. doi: 10.1039/c5cc02016f. 